\title{
Revenue, relevance and reflecting community: Blockbusters at the Art Galley of NSW
}

\author{
Chiara O'Reilly*, Anna Lawrenson**
}

\begin{abstract}
Museums are judged not solely on the basis of their exhibition quality and collection care but, within a corporate model, they are also judged on quantitative measures such as audience numbers and, in turn, their financial viability. Programming has, therefore, become a major focus of forward planning and the basis for funding development. Blockbuster exhibitions, strategically placed throughout annual programs, have been a common way to increase audience numbers and sustain support. In more recent times, the blockbuster model has developed to address more complex measures of success beyond their quantifiable benefits. In addition to the aim of increasing visitor numbers, the blockbuster exhibition and its associated public and education programs, have been effectively utilized as a means of broadening and diversifying audiences. Such efforts help museums to meet expectations, often set by governments, to address and reflect the diverse demographic communities within which they are situated and to whom they serve.
\end{abstract}

The Art Gallery of New South Wales (AGNSW) in Australia provides one such example of a museum that is working creatively within the blockbuster model in order to present exhibitions that build on their collection strengths and existing programs, attract large audiences and engage diverse audiences by focusing on community building. This paper uses the AGNSW blockbuster exhibition The First Emperor: China's Entombed Warriors, to examine the role of this format in contemporary museums more broadly. We use this exhibition as a frame by which to analyse how the Gallery has modified the blockbuster model, and indeed built on it, in order to target geographically and culturally diverse audiences. We argue that this has been effectively achieved as a result of the Gallery building blockbusters around their curatorial and collection strengths, by working with external organizations and community groups and by offering a range of activities and opportunities for engagement both within the museum and outside of its boundaries. This exhibition proves that when blockbusters are used creatively to support museum wide efforts to engage culturally and linguistically diverse audiences they can achieve success that is both quantitative and qualitative.

Key words: Blockbuster, multiculturalism, Terracotta Warriors, social inclusion, public programs, community.

\section{Introduction}

Museums are judged not solely on the basis of their exhibition quality and collection care but, within a corporate model, they are also judged on quantitative measures such as audience numbers and, in turn, their financial viability. Programming has, therefore, become a major focus of forward planning and the basis for funding development. Blockbuster exhibitions, strategically placed throughout annual programs, have been a common way to increase 
audience numbers and sustain support. In recent times, the blockbuster model has been developed to address more complex measures of success. In addition to the aim of increasing visitor numbers, blockbusters and their associated public and education programs have been effectively utilized as a means of broadening and diversifying audiences. Such efforts help museums to meet expectations, often set by government funders, to address and reflect the diverse communities within which they are situated and to whom they serve. This article will diverse communities within which they are situated and to whom they serve. This article will importance within the Australian gallery sector. In doing so, it will consider the broader aims anportance within the Australian gallery sector. In doing so, it will consider the broader aims and benefits of working within this format and will also identify some of the negative aspects It will then focus on the innovative use of the blockbuster exhibition as employed by the Art
Gallery of New South Wales (AGNSW), in Sydney, analysing how they have developed the model in an attempt to meet more specific targets such as attracting culturally and linguistically diverse audiences. Finally, the paper will focus on an example from the Art Gallery, The First diverse audiences. Finally, the paper will focus on an example from the Art Gallery, The Firs have employed to widen the scope of the blockbuster and expand its appeal. We ultimately have employed to widen the scope of the blockbuster and expand its appeal. We ultimately argue that while there have been some modifications to the format of the blockbuster, and indeed a broadening of the subject matter covered by these exhibitions, it is the complementary programs that have been most successfully utilized as a means of engaging and including communities of interest. In art museums like the AGNSW, this approach provides a means of retaining the authority of the institution - and the academic and aesthetically focused nature of their exhibitions - while simultaneously allowing for a relinquishing of their authority in other areas. While it is not necessarily the wholesale collaborative approach that has been championed by museologists (Golding and Modest 2013) in recent times, it does represen the foundation upon which future advances can be built.

On a cursory inspection the First Emperor was a quintessential blockbuster exhibition held in the major temporary held in the major temporary corporate and government sponsorship and occurred over the traditional peak period for visitalion, across summer 2010-2011. As is standard for blockbusters, the exhibit promised a collow 13 institutions in Shaanxi province to source a group of terracotta warriors and horses together with over 100 tomb relics and som (AGNSW 2011: 4). The exhibit was curated in-house by the Galley's then director, Edmund (AGNSW 2011;4) The exhibit wenior curator of Chine Art. It was designed by the Erchitect

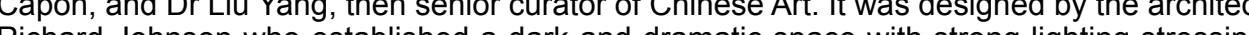
Richard Johnson who established a dark and dramatic space with strong lighting stressing the rarty and beauty of he objects on show. However, when it is contextualized within the wide have been presented within a modified blockbuster model in order to suit broader

\section{Defining Blockbusters and their ongoing relevance}

The Australian art historian, Sasha Grishin (2009) has described blockbuster exhibitions as a 'drug of dependency for the major art galleries' and in Australia the format has been highly successful since the early 1970 s (Turner 2011). Their addictive qualities have hinged on the revenue raising potential of such shows, as well as the increased exposure for the hostmuseum. As Emma Barker has argued, they are 'a scholarly endeavour which serves to educate and entertain the public, bringing prestige and profit to the host institution' (Barker 1999: 127). While Barker indicates why museums might seek to stage blockbusters, Albert Elsen has provided another definition of blockbusters as being about attracting audiences, both new and large He noted in 1984 that they are 'a large scale exhibition that people who normally don't go to museums will stand in line for hours to see' (Elsen 1984:1). Shearer West has seen their appeal to a popular market, and as such their potential to attract new audiences, as one of the innate contradictions of the blockbuster model. Borrowing from Charles Jencks, West (1995: 74-5) argues that the blockbuster represents a form of 'double-coding' in which they are both sites of 'the exclusivity of high culture and the consumerist populism of heterogeneous culture.' This paper argues that it is this very paradox of the blockbuster that enables them to remain relevan within an art museum context. For it enables the museum to engage in a populist dialogue that utilizes 'commercialization, hyperbole and sensationalism' (West 1995: 90) on the one hand but it does so within the comfortable realm of an existing academic model on the other. In order to generate this sensationalism, many blockbuster exhibitions rely on high profile artists and delicately negotiated loans - from either private or other public collections - that provide the hook for marketers to lure in potential visitors with the promise of never - that or rarely seen objects on show for a limited period of time. As Jim Berryman (2013) has also or rarely seen objects on show for a limited period of time. As Jim Berryman (2013) has also He states that these shows are 'Professionally presented and accompanied with glossy catalogues and merchandise... heavily sponsored, aggressively promoted' (Berryman 2013: 159).

When considered in this manner, the blockbuster exhibition is, in essence, a commercial venture. They present opportunities for income generation by capitalizing on audience appeal take advanto of the enthues for income generantion are valt. In Austrities institutions can the local economy, particularly by attracting a significant tourist component The bydney International Art Series is a partnership between the AGNSW, the Museum of Contemporary Art (MCA) and the New South Wales state government that commenced in 2010 and was Art (MCA) and the New South Was state government hibitions to Syc designed specifically to bring large-scale blockbuster exhibitions to Sydney. In that year, they bought . This pertership has since its inception generated 'more than $\$ 80$ million in money. for the State.' Blockbusters are undeniably big business and $\$ 80$ million in new partnerships are in line with broader debates about the economic benefits of staging such partnerships are in line with broader debates about the economic benefits of staging such for growth can be found in their ability to draw first time visitors to these institutions. The First for Emperor and the Annie Leibovitz exhibilion were both very successful in this respect with both exhions to fit within the goals for long-term audience development.

This ability to draw in a substantial crowd also translates into an opportunity to present current scholarship to a large number of visitors. By presenting this scholarship in an accessible format that is, in to lay that peope who don't usully visit muscums will ap accessible format, that is, ip a walfil the blockbuster in in a for fre willeand capacity by rented that that almost all blockbuster exhibilins are accompanied by a lengthy catalogue, which can posith the which equated to the entire print run (AGNSW 2011:16). As Barker has argued museums can produce the tomes in large numbers to meet demand and in tum they ar 'often much more peduce prof the que acty ic qually imics extend the content presented in the exhibition and can go some way to converting first time visitors into an (this to the entire sute of exhibilion colleral and program

exchange, allowing host institutions (he of their own collection. This is crucial in Australia where the format helps to address the geographical isolation and relative youth of many 

Australian collections. The significance of these linkages is twofold. First, relationships with
other institutions enable museums to host exclusive exhibitions in order to attract the large other institutions enable museums to host exclusive exhibitions in order to attract the large audiences (and economic potential) discussed above. Secondly, such partnerships help to establish the reputation of Australian institutions globally and in turn promote their own co facilate relationships outside of the cultural sector and in Australia they have played an to facilitate relationships outside of the cultural sector and in Australla they have played an important diplomatic role. Berrman (2013) has argued that when such exhibitions emerged in Australia ing convincingly power, wh the nathe Importantly, from the very early times there has been an emphasis on developing ties with clo emphas on faciliting particegips in addition to being purely academic and educative an emphasis on faclitating partherships in addilion to being purely academic and educative projects It has only been in more recent years in Australla (Berryman suggests from the

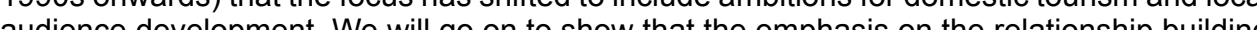
audiente develo potential of blockbuster exhibitions has resulted in a merging of diplomatic and economic goals alongside the development of relationships with local communites of interest within the to foster stonger diplome to foster stronger diplomatic links in addition to addresting the demographics that now characterize the city of Sydney.

Against the positives opportunities of blockbuster exhibitions outlined so far there are of course, significant risks or negative aspects of the format (Bradburne 2001). Globally, these tend to be centred on cost and resourcing issues which have long been identified as aspects which could lead to the death of the blockbuster (Barker 1999: 128). The increasing cost of transport, insurance, and risk management is problematic and potentially unsustainable. forth footprint (Lambert and Henderson 2011). Another aspect of ongoing debate relates to the challenges of balancing ambitions for scholarly work against the realities and pressures of generating strong audien This element in particular has led to a virtual standardization of types of blockbusters with a few key themes often repeated. West (1995: 90) has argued that art blockbusters have been limited to a handful of canon. at the shrine of great art. Across museums more broadly, the subject matter includes rare treasures of ancient civilizations and has expanded in recent years to include celebrations of popular culture focused on movies or pop stars. This high turnover of crowd pleasing shows 'can mean that visitors often only attend museums, as Bradburne (2001) has argued, when 'something's on', which can draw attention away from their everyday work. Cultural institution must, therefore, balance the resources needed to stage blockbusters against the resources they devote to collection-based shows, research and in turn collection care and conservation. This, coupled with the substantial costs of blockbusters, means that even with extensive reliance on sponsorship, they are by no means a guaranteed positive return and can be detrimental to an institution's overall budget (Bradburne 2001; Skinner 2006; Boland 2010).

A final negative, which must not be underestimated, is the actual physical experience of the visitors when viewing objects within this large-scale, often crowded, format. The consequences here, as Barker (1999: 140) has suggested, are considerable. First, due to the large scale nature of these exhibitions the visitor is often fatigued which has a detrimental effect on thei experience of the exhibition and the narrative it attempts to establish. Secondly, because of their high volume of visitors it is difficult to have an intimate and concentrated experience with the objects on show. As West (1995: 90) has eloquently put it, 'the overwhelming spectacle of crowds, queues and commodities prevent them from engaging meaningfully with the works on display.' Such negative physical experiences could have a harmful impact on overall visito perceptions and could reduce repeat visitation, particularly by new audience segments that institutions are so keen to retain.

\section{Expanding the field: Blockbusters at the Art Gallery of New South Wales}

Despite these challenges in Australia, as elsewhere, blockbusters remain central to the work of museums and galleries. The AGNSW has been a vanguard subscriber to this exhibition format, being a host venue for some of the first exhibitions of this type in Australia. In 1975, was part of the touring program for Modern masters: Manet to Matisse, and in 1977 it hosted The Chinese exhibition: a selection of recent archaeological finds of The People's Republic of China. The latter exhibition attracted a considerable audience of 227,080 people making it the most successful exhibition held at the Gallery during the 1970s (AGNSW 2009: 10). It was closely followed by the, then, director Edmund Capon's own special project Qin Shihuang Terracotta Warriors and Horses in 1983, which was remarkably the first ever exhibition of the terracotta warriors outside of China. Unlike The Chinese Exhibition of 1977, Qin Shihuang was curated and organized in-house by the AGNSW in collaboration with Chinese officials. In Sydney, it attracted a substantial 202,583 visitors before it successfully toured around Australia (AGNSW 2009: 10). The exhibition also represented a broader political symbolism as it marked ten years since the establishment of diplomatic relations between Australia and China (Capon 1982: 4). As a counterpoint to West's claims about the limited subject matter of blockbusters, the AGNSW can be seen as an early innovator through their presentation of exhibitions from outside of the canon of western modern art. In doing so, the Gallery also attempted to demonstrate their cultural literacy and speak to the growing multicultural population of Sydney. This has continued and is now in line with government policy with the AGNSW bound to adhere to the principles of multiculturalism stated in the 'Community Relations Commission and principles of Multiculturalism Act of 2000'. These principles recognize and value the cultura and linguistic diversity of the local population and seek to facilitate participation by all members of the community in an inclusive fashion. Adherence to these principles can be seen at all levels of the Gallery's activities - through collection development, exhibitions and programs. As Capon identified in the Gallery's Corporate Plan, it was their aim to 'share' the work of the . The foundation upon which this engagement was based was their strong collection of Asian art and curatorial expertise.

The AGNSW's collection of Asian art dates back to the years of its foundation when objects were gifted in 1879 by the Japanese government. In 1972, a dedicated space was opened to show the expanding collection and an Asian curatorial department was established in 1979 (Guy 1981). This coincided with the appointment of Capon, a passionate scholar of Asian art, as Director of the Gallery. He prioritized the collection and exhibition of Asian art as a core part of the institution's identity stressing its importance to the future of the Gallery:

It is wholly appropriate that Sydney, and indeed Australia, should become increasingly aware of her Asian neighbours. An appreciation of those countries'

understanding from which we all shall benefit. (Capon 1979: 3)

Capon's statement and the expansion of the Gallery in this direction, reflects shifts in Australian identity and its political and cultural agenda.

This was reinforced in their exhibition program which, based on their curatorial expertise, meant that they were well placed to use the blockbuster format to develop new audiences for Asian art. They have been leaders in this area since the 1980s. Caroline Turner noted that it was then that the:

AGNSW took a major lead in presenting Asian exhibitions. The NGV [Nationa Gallery of Victoria] at the time had the more important collection of Asian art but it was the AGNSW that began to present an array of exciting Asian exhibitions, including from China, Japan and India. (Turner 2011)

Prioritizing art outside of the canon can be seen as a way of celebrating difference and community diversity, countering what Sandell (2002: 8) has described as 'the museum's part in excluding stereotyping or silencing difference through the selection, arrangement and public display of objects. 
Asian art and cultural themes have been a regular feature of the blockbuster schedule at the AGNSW. This demonstrates their sustained desire to engage with diverse communities while the accompanying public programs provide an opportunity to build more meaningfu relationships with multicultural audiences. This trend starts with The Chinese Exhibition and Qin Shihuang discussed earlier, and is then evident in a number of large-scale exhibitions including Dancing to the Flute: Music and Dance in Indian Art (1997). This was followed by BUDDHA: Radiant Awakening (2001-2002), which was the first blockbuster supported by VisAsia, the Gallery's dedicated sponsorship group whose aim is to promote the appreciation of Asian visual arts and culture through exhibitions, events and education. Other shows that of Asian visual arts and culture through exhibitions, events and education. Other shows that could be grouped in this series include Goddess Divine Energy (2006-2007), the externally
curated Arts of Islam: The Nasser D Khalili Collection (2007) and the most recent The Firs curated Arts of Islam: The Nasser D Khalili Collection (2007) and the most recent The First Emperor: China's Entombed Warriors. As a group of exhibits, they demonstrate the serious investment that the Gallery has made in this curatorial area. They also demonstrate thei eagerness to engage new audiences by generating an accessible and attractive space for an important challeng:

Our problem is very clear, that we don't get the Chinese community in here. We

don't get the Indian community in here. We don't get the Vietnamese community

in here; we just don't do it. Somehow, you see, we're perceived to be a kind of

European cultural institution. (Ang 2005: 315)

To combat this, each exhibition specifically targeted a segment of the community underrepresented in the Gallery's standard audience but who are well established in the community. For example, these shows were aimed at some of the major migrant groups in the greater Sydney region which, in the 2011 census, included people from China, India and Vietnam amongst its top five. The marketing and development of public programs and events involved community participants and were used as a platform to focus on community harmony understanding and encouraging access. There is an extensive body of literature about social inclusion in museums (Sandell 2002; Watson 2007; Crooke 2008; Golding and Modest 2013) and the AGNSW allows us to consider what museums are actually doing in this area and more importantly how are they incorporating these principles into their everyday practice.

\section{Experimentation within the Blockbuste}

This sequence of blockbuster exhibitions were firmly integrated within the identity of the Gallery - borrowing all of the traditional language and forms deployed for their more customary, canonical, counterparts. In this sense the exhibits, like any large scale exhibition at the Gallery, became an 'experience' that offered a full calendar of associated events and programs aimed at providing physical and intellectual access to the widest possible audience. Furthermore in colonizing the mainstream blockbuster spaces, they symbolically and literally shifted the Gallery's identity, as reflected in their programming, and in turn set new ambitions to become more inclusive. The First Emperor benefited from the Gallery's experience with the blockbuster format generally and the innovation that has occurred in relation to Asian themed blockbusters more particularly.

One of these exhibitions, BUDDHA: Radiant Awakening, demonstrates a number of these important innovations. The Gallery used it as a forum to advance understandings of experimentations included the incorporation of a community space a program of community guiding in first language and opening the Gallery outside of traditional hours.

BUDDHA was the first blockbuster to incorporate a community space within the main exhibition gallery. This 'Wisdom room' was set aside for Buddhist community associations to exhibition gallery. This 'Wisdom room was set aside for Buddhist community associations to inhabit and engage with visitors sharing their own knowledge and experience of Buddhism. According to Ang, this tactic was particularly successful in making the exhibit more inclusive as it brought these communities inside the space of the dominant culture and showcased the efforts to break down some of the barriers that can dis its capacity to offer a more meaningful engagement with the subject matter of the exhibition. Thus, shifting the focus away from the authority of the Gallery and towards a more participatory model in which the dissemination of information was not always regulated.

The exhibition was also a forum for their first experimentation with the use of volunteers to offer community language led tours. Importantly, they were designed to help encourage 'new visitors across the threshold' (MacArthur 2005). For its champion at the Gallery Ann MacArthur, it has become an exercise in 'stimulating cultural citizenship' (MacArthur 2005), Merspective which is in line with Sandell's ideas of the museum's capacity to engender 'engendering 'a sense of place and belonging' (2002:3). The tours were extremely engender 'engendering 'a sense of place and buck 's regular offerings under were extremely successfu Ambassadors program'. From 2003 to 2014 this program has been responsible for introducing 12,000 new visitors to the Gallery (Community Ambassadors at Ten, 2014: 26). Perhaps more importantly, the Community Ambassadors program has helped to develop a sustained mole imphip with non-English speaking audiences who comprise a significant proportion of the community. Currently tours are offered in Cantonese, Mandarin, Japanese and Korean with community. Currently tours are offered in Cantonese, Mandarin, Japanese and Korean with plans to expand the program further. By speaking to communities in their own language, this program can offer a highly personalized experience, facilitated by the committed volunteers who are strong advocates for the Gallery. As one participant commented: 'I can't believe I am hearing someone talk to me about art in my own language' (Sykes 2004: 10). The Gallery's recognizing that language is a considerable barrier to access and participation. Nightingale's recogearch reinforces this by highlighting the value of working with dedicated community members es we the use of community languages in facilitating access for culturally and linguistically diverse audiences. (Nightingale 2006)

The final innovation to come out of the BUDDHA exhibition was the commencement of the 'Art After Hours' program. This consisted of opening the Gallery outside of usual business hours to pritent a program of celebrity lectures exploring 'n $n$ all and diverse ways Buddhism hou impated on Western ofiety'. The event was highy succesful attracting 4,500 visitor has imSW 2002: 20). It has now become a stalwart of their programming and has expanded to include a variety of points of access such a film programs, music, performances, celebrity to inclucs lectures, at appocition. 5ta This focus on demonstrating the relevance of their exhibitions within such social settings provides another example of how the Gallery has relinquished some of its authority. It has provides ance inclusive place in which space is given over to thempression of a diversity ef pers a more ince (2006: 360) has arued, involves the museum. The che (2006: 360) has af differences in ofues and museum as an intifulion and the audiedge, which use it' (Wito muserced as an in communities are invited to control how their perspective is represented on the public stage that is the museum.

\section{The First Emperor and Community Engagement}

With this understanding of the Gallery's attempts to become more accessible through noncanonical blockbuster exhibitions and their associated programs it is possible to position the First Emperor as more than simply a populist show with an exclusively economic imperative. Rather, it can be seen as a continuation of the Gallery's strategy, as established above, to use blockbuster exhibitions to reach out to new audience segments and broaden participation It did this by employing a variety of modes of address within their marketing, programming exhibition design and collateral.

The first indication that the Gallery was seeking to attract diverse communities was seen in the marketing of the exhibition and its associated events. The range of visitor experiences 

campaign, which sought to entice a broad audience. In doing so, it included traditional forms
of publicity like advertising and editorial in major newspapers. The Gallery also capitalized on community-based ming a cla oxhibition beyond their usual networks and establish a relationship with potential visitors before they entered the space. Within this campaign, Chinese-speaking audiences were before they entered the space. Within this campaign, Chinese-speaking audiences wer explicitly targeted. The Gallery advertised the show nationally in the Australian Chinese Daily and Sing Tao Daily - currently the largest circulating Chinese language daily newspapers in Australia. According to the Gallery's Media Relations Manager they were also able to extend their advertising coverage to other media outlets including a substantial radio component through the support of Events New South Wales. This saw the show promoted on Chinese language radio stations including 2CRN China Radio Network, SBS Radio-Cantonese, SBS Radio-Mandarin and 2AC (Mandarin and Cantonese). As a result of this investment, the show also received a considerable amount of editorial attention beyond the mainstream media. For which also included an article on the show itself and a full page profile on the Gallery's Senior which also included an article on the show itself and a full page profile on the Gallery's Senio including Oriental BQ Magazine (2010) and Vie Lifestyle Magazine (2011). This attempt to including Oriental BQ Magazine (2010) and Vie Lifestyle Magazine (2011). This attempt to literally speak the language of the targeted audience was further built upon in the physical elements, as did the exhibition The didactic panels in the show included the use of bilingua

[Language] signifies cultural identity, prestige, and power, defining social boundaries that include and exclude... Bilingual exhibits don't just make content e conveying who belongs in our learning institutions.' (Renner et.al. 2012: 14)

Such inclusions are rare in exhibitions in Australia and, as such, demonstrate the investmen Such inclusions are rare in exhibitions in Australia and, as such, demonstrate the investment
that the Gallery made in seeking to change their mode of address and thus present themselves that the Gallery made in seeking to change their modec
as more inclusive of Chinese speaking audiences.

Another strategy for the expansion of audience can be seen in the engagement of community groups in the delivery of public programs. Like the Community Ambassadors discussed above, the people engaged to deliver those programs can be transformed into advocates of both the exhibition and the Gallery, again serving to minimize the barriers to access through familiarity at the point of access. The desire to develop programs that 'extend existing audiences and build new audiences, particularly in under-represented groups' (AGNSW 2010) was a strategic priority of the Gallery identified in their corporate plan. This strategy was evident in the adaptation of existing programs but also in the formulation of new events specifically for this exhibition. Art After Hours was one of the existing program formats that was adapted to the themes of the exhibition. These evenings were unified by a thematic focus on China and its heritage, as evident in Australian culture, with a particular emphasis on the experience of being Chinese-Australian. The aim of these events was to locate the themes of the warror exhibition within a local and contemporary context. Thus, the main hall of the Gallery became the venue for a series of special celebrity talks offering a personal reflection on the exhibition themes and contemporary Chinese identity, which involved community leaders and well-known identities. The cafe was transformed into the Shanghai Nights Bar where visitors could extend their cultural experience into a culinary adventure through the contemporary mim sum menu. The cafe space also became a venue for pefformances by musicians like master bamboo flute player Chai Chang Ning. Finally, a free film series was presented that interrogated cinematic representations of Chinese history. By offering a range of activities; culural, cullinary, entertainment and education, the Gally reflects shits in the provision of leisure services in which, as Falk (2009: 43) has argued, 'we engage in a blending of goals and activities through a kind of consumptive multitasking. 'Working within this existing event timeslot meant that regular gallery goers could still expect a comparable experience and the Galley thus ensured that hey would not exclude their loyal visitor base. But th also included specific community groups in their delivery and were marketed to those groups

This strategy of community involvement was most clearly implemented during one of the unique programming opportunities for the exhibition - a full weekend of activities associated with Lunar New Year. The Gallery recognized that this was a core part of the community's calenda and they framed this weekend as a major highlight of the First Emperor exhibition Over the weekend, they hosted a large number of activities including performances, demonstrations, weekend, they hosted a large number of activities including performances, demonstrations, workshops and tours. Many of these programs, such as the fan dancing workshop, depended on the participation of invited community groups to lead performances and participatory
workshops. These groups were often based in the outer suburbs of Sydney - well outside of the workshops. These groups were often based in the outer suburbs of Sydney - well outside of the they provide an opportunity for the performers to familiarize themselves with the Gallery (and perhaps invite friends and family), they also provided an opportunity for the Gallery's regula perhaps invite friends and family), they also provided an opportunity for the Gallery's regular loyal audience to actively participate in these programs. These events, therefore, created a unequal sources of power and disparate cultural identities could take place' (Ang 2005: 314 ). unequal sources of power and disparate cultural identities could take place' (Ang 2005: 314). a more accessible institution and secondly, to encourage community harmony and cultura a more accessible institution and secondly, to encourage community harmony and cultura understanding through the shared experience of each program. As Serena lervolino (2013 121) has argued, in relation to a similar program of community engagement, such a process is with the museum and insteause it transforms the performers from having a passive relationship 'sh the museum and instead positions them in an active role in which they are crucial to the 'shaping and sharing [of] knowledge.' Moreover, through the broad reaching platform of the museum, this participatory model enables community members to address not just 'members

(he Lunar New Year weekend event (and to see the exhibition generally) meant that conducting programs within the actual exhibition space was difficult and deemed too high a risk to the objects. This, however, also represented an opportunity for the Gallery to present themselves as a more accessible place by allowing the whole building to be populated and co-opted into the service of public programs beginning at the front steps and permeating all of the main halls of the Gallery. The result was a festive at the front steps and permealing all of the main halls of the Gallery. The result was a festive it from the quiet, conth more he qu mo space a preth hil and being with people' (Falk 2009: 49). By offering a range of goup-based social (Fentia activities within this festive environmen of this desired audience segment.

At the conclusion of events on Sunday, visitors were encouraged to leave the Gallery and head to the Sydney Town Hall for the commencement of the city's Twilight Parade. This is a key part of Sydney's Chinese New Year Festival, which is widely recognized as the largest
of its kind outside of Asia (City of Sydney 2010: 3). Here, the Gallery literally took the First Emperor exhibition to the streets with a dedicated float featuring their own Entombed Warrior and a complement of Gallery representatives. Their participation marketed the exhibition to another audience and highlighted its relevance to Chinese communities and those interested in Chinese culture more generally. In linking with this event, the Gallery was actively positioned within the wider cultural landscape of the city and thus their reach was expanded.

Hosting this weekend represented a huge commitment in terms of resources and staff but it resulted in spectacular success attracting 13,000 participants (AGNSW 2011 25). There is a strong claim to be made for the packaging of public program events within a festival context as a means of attempting to overcome social exclusion and attract visitors from underrepresented regions. The traditional audience for the Gallery has come from the more affluent Eastern and Northern suburbs of Sydney with people from Western Sydney being an identified underrepresented audience segment (AGNSW 2011:20). Western Sydney is known to be a particularly diverse region of the city with migrants representing one third of its overall population and 'half of the world's nations... represented among its residents.' A recent study authored by Multicultural Marketing and Management (MMM) for Arts NSW, focused on Western Sydney, surveyed people who had been designated as non-attendees - 
those who do not regularly attend museums or cultural activities more broadly. The study found that these non-attendees would be more willing to attend festivals than other cultural events. I concluded that more than two thirds of non-attendees ( 66.8 per cent) would be likely to attend a festival in the next 12 months compared with only a quarter ( 26.6 per cent) of respondents likely to attend an art gallery (MMM 2009: 41). Promoting festival based programs within gallery can therefore, be seen as a strategic effort to attract non-attendees. It is also in line with current trends in the leisure industry in which 'experiences are being packaged in ways the current trends in the leisure industry in which "experiences are being packaged in ways that If one of the goals of the exhibition was to appeal to a diverse audience, presenting programs in an attractive fetival setting and including performers from underrepresented regions can be seen as a clear strategy for diversification.

\section{Innovation alongside the blockbuster}

While events on a grand scale can attract large audiences, there is little scope to generate intimate and individual experiences when presenting such activities. This was addressed by the Gallery in what can be seen as the last innovation of the First Emperor exhibition. This was not a feature of the exhibition itself but rather a decision by the Gallery to host a concurrent show on a related theme within the Asian Gallery's temporary exhibition space. This show, Homage to the Ancestors Ritual art from the Chu Kingdom, was a smaller, more specialist scholarly exhibition which ran from February to late April 2011. Here, outside of the blockbuster space, they were able to create a more intimate setting in which to experience Chinese art that was closely aimed at attracting a Chinese speaking audience. This is evidenced by the promotion of a regular program of weekly Community Ambassador led tours which were well attended and provided an opportunity for participation that was simply not possible in the larger Firs Emperor show. Because of the close relationship between the two exhibitions, many of these public programs were marketed as being relevant to both shows. This meant that the smaller scale public programs with a specialist interest, such as the Community Ambassador tours could still serve to familiarize new audiences with the Gallery spaces in the hope of encouraging repeat visitation in future. This exhibition was also the host of the annual VisAsia Hing Yiu Mok Mandarin language lecture, which was given by Wan Quanwen, the Deputy Director of the Hubei Provincial Museum as part of the Chinese New Year celebrations at the Gallery. Not only did this lecture appeal to Mandarin speakers and the academic community but it also served to firm up the relationship between the Gallery, Sydney City Council and the Chinese province of Hubei, who were partners in both the exhibition and the city-wide New Year festival.

\section{The wider lessons from the approach taken at the Art Gallery of New South Wales}

From these examples, it is clear that blockbuster exhibitions can fulfil a number of importan functions for museums and galleries and, although the case is presented from an Australian perspective, the lessons are by no means confined to this context. As institutions in Australia and internationally are increasingly forced to generate their own revenue - and do so in a manner that reflects their mission, collection and communities - the AGNSW provides a mode for building on established income generating opportunities, like the blockbuster exhibition, in order to make them more relevant to missions and markets while exploiting institutiona knowledge and collection strengths. Such exhibitions provide vital opportunities for museums to attract large audiences and can generate revenue in the face of diminishing government support but, as we have seen, they can also fulfil objectives around appealing to new, diverse and previously underrepresented audience segments.

Statistics from the AGNSW confirm that this exhibition did attract an expanded audience beyond their standard demographic profile. In fact, the number of visitors from Western Sydney equalled the number of visitors from their usual geographical stalwarts (AGNSW 2011: 20). Moreover, 54 per cent of visitors came from outside of the Sydney Metropolitan area and 33 per cent were visiting the Gallery for the first time, specifically to see the Warriors exhibition (AGNSW 2011: 19). Although it did attract a wider segment of the population, the test for the Gallery in the longer term is whether they can retain the relationship with these new visitors, transforming them into loyal followers. It is in this regard that the promotion of their permanent collection, as a key centre for Asian art, their investment in Community Ambassadors and their ongoing range of smaller temporary exhibitions will take on even more importance in maintaining relationships with communities.

The innovations implemented to attract this diverse audience have been incremental, sustained and integrated into the corporate structure of the Gallery. They may be seen as conservative, and certainly do not constitute a wholesale relinquishing of the authority of the is woven into the fabric of the institution. This has been further reinforced in the new Director's vision for the Gallery. Under the Direction of Michael Brand, who was appointed in mid-2012 it is hoped that the Gallery will expand to enable increased space for major national and international exhibitions as well as the permanent collection. In addition, they have identified international exhibitions as well as the permanent collection. In addition, they have identified a desire for further innovation in the areas of community engagement through education as well as new forms of participation - all goals that we have seen developed around The Firs years they continue to build on their incremental approach in order to further develop meaningfu years they continue to build on their incremental approach in order to further develop meaningfu dismissed in future as simply paying lip service to engagement strategies or in the words of Lynch and Alberti, 'participation-lite' (2010: 17).

Received : 8 November 2012

\section{References}

(2010) Australian New Express Daily, 1 December: 1, 6, 18

(2010) Oriental BQ Magazine, 12 November: 55.

(2011) Vie Lifestyle Magazine, Issue 6: n.p.

(2014) 'Community Ambassadors at Ten', Look: Art Gallery Society of New South Wales, 2 26-27.

Ang, I. (2005) 'The Predicament of Diversity: Multiculturalism in Practice at the Art Museum', Ethnicities, 5 (3) 305-320.

Art Gallery of New South Wales (2002) Annual Report 2001-2002, Sydney: Art Gallery of New South Wales.

Art Gallery of New South Wales (2009) Monet and the Impressionists: Exhibition Report Sydney: Art Gallery of New South Wales.

Art Gallery of New South Wales (2010) Corporate Plan 2010-2015, Sydney: Art Gallery of New South Wales.

Art Gallery of New South Wales (2011) The First Emperor: China's Entombed Warriors: Exhibition Report, Sydney: Art Gallery of New South Wales.

Barker, E. (1999) 'Exhibiting the Canon: The Blockbuster Show', in E Barker (ed) Contemporary Cultures of Display, 127-49, New Haven: Yale University Press.

Berryman, J. (2013) 'Art and national interest: the diplomatic origins of the "blockbuster exhibition" in Australia', Journal of Australian Studies, 37 (2) 159-173.

Boland, M. (2010) 'Blockbusters Art Shows are no Cash Cows', Australian, August 9, 3.

Bradburne J.M. (2001) 'A New Strategic approach to the Museum and its Relationship to society', Museum Management and Curatorship, 19 (1) 75-84.

Capon, E. (1979) 'Message from the Director' Art Galley of New South Wales Information Bulletin, Sydney: Art Gallery of New South Wales, 2-3. 
Capon, E. (1982) Qin Shihuang: Terracotta Warriors and Horses, Sydney: International Cultural Corporation of Australia Limited.

City Of Sydney. (2010) Chinese New Year Festival Year of the Rabbit Program. 28 Jan-13 Feb, Sydney: City of Sydney, booklet.

Crooke, E. (2008) Museums and Community: Ideas, Issues and Challenges, London: Routledge.

Elsen, A. (1984) 'The Pros and Cons of the 'Blockbuster' Art Exhibition', Art Museums Association of Australia Occasional papers, 1-18.

Falk, J. (2009), Identity and the Museum Visitor Experience, Walnut Creek: Left Coast Press.

Golding, V. and Modest W. (eds) (2013) Museums and Communities: Curators, Collections and Collaboration, London: Bloomsbury.

Grishin, S. (2009) 'The rise and rise of the blockbuster', Australian Art Review (9 February) http://artreview.com.au/contents/271278412-the-rise-and-rise-of-the-blockbusterexhibition

Guy, J. (1981) 'Asian Art in Australian Public Collections', ASAA Review, 5 (July) 19-22.

lervolino, S. (2013) 'Museums, Migrant Communities, and Intercultural Dialogue in Italy', in and Collaboration, 113-129, London: Bloomsbury.

Lambert, S. and Henderson J. (2011) 'The carbon footprint of museum loans: a pilot study at Amgueddfa Cymru-National Museum Wales', Museum Management and Curatorship, 26 (3) (August) 209-235.

Lynch, B. and Alberti, S. (2010) 'Legacies of prejudice: racism, co-production and radical trust in the museum' Museum Management and Curatorship, 25 (1) (March) 13-35.

Macarthur, A. (2005) 'Including language: the Community Ambassadors program at the Art Gallery of New South Wales', Conference Paper - SITES of Communication 2 conference, Sydney: Art Gallery of New South Wales.

Multicultural Marketing and Management (2009) Who doesn't attend and why? A Strategic Study of Non-Attendees at Cultural Venues and Events in Western Sydney, Sydney:

Museums and Galleries New South Wales (2009) Guess Who's Going to the Gallery? A Strategic Audience Evaluation and Development Study for Galleries in NSW. Year 2 - Sydney Metro Region Abridged Report, Sydney: Museums and Galleries New 2-Sydney Metr

Nightingale, E. (2006) 'Dancing around the collections: developing individuals and audiences' in H. Aldershot, J. Reeve and V Woollard (eds) The Responsive Museum: working with audiences in the twenty-first century, 79-91, Farnham: Ashgate.

Renner, N., Plaza, C., Garibay, C. and Yalowitz, S. (2012) Bilingual Exhibits: Current Practices, Collective Knowledge, Outstanding Questions, National Science Foundation Grant DRL\#1010666 http://archive.informalscience.org/ documents/0000/0170/Bilinqual Exhibits current practices 2012.pdf
Sandell, R (2002) 'Museums and the Combating of Social Inequality: roles, responsibilities, resistance', in R Sandell (ed) Museums, Society, Inequality, 3-23, London: Routledge.

Skinner, S. (2006) 'Estimating the real growth effects of blockbuster art exhibits: A time series approach' Journal of Cultural Economics, 30 (September) 109-125.

Sykes, J. (2004) 'Community Ambassadors. Different languages open up the Gallery collection', Look: Art Gallery Society of New South Wales, 5 (May) 9-1.

Turner, C. (2011) 'International Exhibitions', in D. Griffin and L. Paroissien (eds.) Understanding Museums: Australian Museums and Museology, Canberra: Nationa Museum of Australia. http://www.nma.gov.au/research/understanding-museums/ CTurner_2011.html

Watson, S. (ed) (2007) Museums and their communities, London: Routledge.

Witcomb, A. (2006) 'Interactivity: Thinking Beyond', in S. MacDonald (ed) A Companion to Museum Studies, 353-361, Malden: Blackwell.

West, S (1995) 'The Devaluation of "Cultural Capital": Post Modern Democracy and the Art Blockbuster', in S Pearce (ed) Art in Museums, 74-93, London: The Athlone Press.

\section{Notes}

' (2013), Exclusive international exhibitions headline Sydney Art Series 2013-2014, Destination NSW, viewed 21 January 2014, http://www.destinationnsw.com. au/news-and-media/latestnews/exclusive-international-exhibitions-headline-sydney-art-series-2013-2014.

2 Sydney international art series backgrounder, viewed 15 July 2014, http://archive.eventsnsw. com.au/Media-Centre/Media-Releases/08-08-11-Sydney-International-Art-Series-201112-B.aspx.

${ }^{3}$ (2000), Community Relations Commission and Principles of Multiculturalism Act 2000 (no.77), New South Wales Government, Australasian Legal Information Institute, viewed 21 January 2014, http://www.austlii.edu.au/au/legis/nsw/consol_act/crcapoma2000722/.

${ }^{4}$ (2013), 2011 Census Quick Stats: Greater Sydney, Census, Australian Bureau of Statistics viewed 21 January 2014, http://www.censusdata.abs.gov.au/census services/getproduct census/2011/quickstat/1GSYD?opendocument\&navpos $=220$

${ }^{5}$ So far this has been the only exhibit to incorporate a Community Space within the blockbuster itself. However the recent exhibition America: painting a nation (2013-2014) does suggest some changes under the new director - with children's panels included within the exhibition and a lounge space where there is reading material. This perhaps hints a future developments to come.

${ }^{6}$ (2013), Volunteer Gallery Guide Training Program 2013: Information Pack, Art Gallery of New South Wales, viewed 21 January 2014, http://www.artgallery.nsw.gov.au/media/downloads/ files/Volunteer-Guide-Training-Program-2013-info-pack.pdf.

${ }^{7}$ Gibson, L. and Russel, K. (2004) Art Gallery of New South Wales - Art After Hours, Australia Council for the Arts, viewed 21 January 2014, http://www.australiacouncil.gov.au/resources/ reports and publications/subjects/marketing/audience development/art gallery of new south wales - art after hours. 
${ }^{8}$ Gibson, L. and Russel, K. (2004), Art Gallery of New South Wales - Art After Hours, Australia Council for the Arts, viewed 21 January 2014, http://www.australiacouncil.gov.au/resources/ reports and publications/subjects/marketing/audience development/art gallery of new south wales - art after hours.

${ }^{9}$ (n.d.) Chinese Newspapers in Australia, 999 Australian Chinese Advertising Agency, viewed 21 January 2014, http://english.999advertising.com.au/entry/chinese market in australia.

10 Martin, C., Media Relations Manager, AGNSW, Personal Communication, 14 October 2011.

11 (2010) The First Emperor Celebrity events, Art Gallery of New South Wales, viewed 21 January 2014 http://www.artgallery.nsw.gov.au/calendar/first-emperor-celebrity-event/.

${ }^{12}$ The traditional audience for the gallery comes from the North Shore, Inner West and Eastern Suburbs of Sydney (AGNSW 2011: 20). Moreover, according to a recent Museums and Galleries New South Wales report, arts audiences in Sydney are less diverse than the general population demographic when measured in relation to languages spoken at home. Some 22 per cent of surveyed visitors to Sydney galleries spoke a language other than English at home as compared to the national Australian Bureau of Statistics statistics which show that 29 per cent of the population speak a language other than English at home (Museums and Galleries New South Wales 2009: 5).

${ }^{13}$ (2011), Chinese New Year at the Gallery 2011, Art Gallery of New South Wales, viewed 21 January 2014, https://www.flickr.com/photos/artgalleryofnsw/sets/72157626072240204/.

14 (n.d.) Demographics - Western Sydney, New South Wales Government Department of Premier and Cabinet, viewed 21 January 2014, http://www.westernsydney.nsw.gov.au/ about-western-sydney/demographics/.

15 (2013) Gallery unveils strategic vision and masterplan, Art Gallery of New South Wales, viewed 21 January 2014, http://www.artgallery.nsw.gov.au/media-office/agnsw-unveilsstrategic-vision/.

*Dr Chiara O'Reilly is a Lecturer in the Museum and Heritage Studies program at the University of Sydney. She has been involved with this program since 2007. Prior to this she completed her PhD (2006) in which she examined the work of French Romantic Landscape painter Paul Huet (1803-1869). She has also worked within cultural organisations on a variety of exhibitions.

Department of Art History \& Film Studies

The University of Sydney

R.C. Mills Building, A26

NSW, Australia, 2006

Email: chiara.oreilly@sydney.edu.au

**Dr Anna Lawrenson is a Lecturer in the Museum and Heritage Studies program at the University of Sydney. She completed her PhD in 2007 through the Centre for Cross-Cultural Research at the Australian National University. She has worked in curatorial, research and management roles within the arts sector in addition to teaching at a number of tertiary institutions.

Department of Art History \& Film Studies

The University of Sydney

R.C. Mills Building, A26

NSW, Australia, 2006

Email: anna.lawrenson@sydney.edu.au 